\title{
Cianobacterias en suelos arroceros de Entre Ríos
}

\author{
Sánchez, Cecilia I. \\ Fac. de Cs. Agropecuarias. Universidad Nacional de Entre Ríos. Ruta 11. Km 10. (3101). Oro Verde. Entre Ríos. \\ E-mail: cecilias@fca.uner.edu.ar
}

Conferencia dictada en el marco de la XI Reunión Nacional Científico-Técnica de Biología de Suelos. Corrientes (Argentina)- Octubre de 2017.

\section{RESUMEN}

Los arrozales se consideran humedales artificiales someros que favorecen el desarrollo de organismos autotróficos como microalgas eucariotas y cianobacterias. Ambos grupos microbianos contribuyen a la productividad primaria del sistema. Las cianobacterias, por su parte, aportan además a la fertilidad de los suelos por el proceso de fijación biológica de $\mathrm{N}$ que llevan adelante. La dinámica de estos microorganismos está afectada por variables ambientales y las prácticas agrícolas realizadas en los lotes arroceros. Durante gran parte del período de crecimiento del arroz, el cultivo se encuentra sumergido en agua con una altura de lámina que oscila entre los 5 y $10 \mathrm{~cm}$, la que es drenada poco antes de la cosecha del mismo. El conocimiento sobre la microflora autotrófica en este tipo de agroecosistemas está descripta para países asiáticos y Europa. Sin embargo, en suelos agrícolas de climas templados la información disponible es limitada. La producción de arroz en Argentina tiene características peculiares y se realiza principalmente en las provincias de Entre Ríos y Corrientes. En la primera, se emplea como fuente de agua para el riego para el cultivo agua subterránea. El recurso hídrico proviene de pozos de una profundidad de entre $60 \mathrm{y}$ 80 metros. La evaluación de los grupos microbianos de características autotróficas se realiza según la propuesta del International Rice Research Institute. La evaluación de las variables contenido de pigmentos fotosintéticos y abundancia potencial de cianobacterias proporcionan información sobre la comunidad autotrófica del suelo. El contenido de los pigmentos fotosintéticos clorofila $a$ y feopigmentos son considerados como medida de la biomasa algal y su estado fisiológico. La abundancia potencial de cianobacterias en medio de cultivo selectivo sin $\mathrm{N}$ permite cuantificar y caracterizar el pool o reservorio de cianobacterias heterocistíneas presentes en el campo. Estas dos variables biológicas son reactivas a la humedad y $\mathrm{pH}$ del suelo, contenido de $\mathrm{C}$ orgánico, la radiación solar y el manejo de los lotes. En suelos sin intervención antrópica (monte) se sustenta mayor contenido de clorofila $a$ y feopigmentos, indicando que se desarrolla una comunidad algal madura. Luego de la labranza en los lotes arroceros el contenido de feopigmentos es mayor al de clorofila $a$ indicando que la comunidad algal atraviesa un estrés fisiológico. Los recuentos son variables con el ciclo del cultivo, la temperatura del agua y las prácticas agronómicas. Los lotes en los que se implementan rotaciones con una alta participación del cultivo de arroz (monocultivo de arroz) presentan mayores recuentos potenciales de cianobacterias, sugiriendo el efecto positivo de este cultivo sobre el grupo de cianobacterias fijadoras de N. La situación de menor intervención antrópica (monte) es la que comparativamente presenta menor recuento respecto de la rotación monocultivo de arroz. La identificación de los morfotipos de cianobacterias se realiza por sus características morfológicas. Los morfotipos de cianobacterias hallados corresponden a los grupos unicelulares, filamentosas no heterocísticas y filamentosas heterocísticas. A partir de la labranza de los lotes se reconoce una sucesión algal, diferente a la descripta para otras áreas arroceras. Luego del paso de la maquinaria para emparejar el lote y la posterior construcción de taipas sumada a las altas intensidades lumínicas al que está expuesto el suelo se desarrollan únicamente diatomeas. Durante el estado vegetativo del cultivo además de diatomeas crecen cianobacterias unicelulares, las cuales toleran condiciones de baja disponibilidad de humedad del suelo. Cuando los lotes son inundados se favorece el desarrollo de filamentosas no heterocísticas, cuyo crecimiento obedece a la presencia de vacuolas de gas que le permiten regular su posición en la columna de agua. El estudio de las cianobacterias nativas aporta al conocimiento de la ecología de estos microorganismos en suelos arroceros de Entre Ríos. La información generada contribuye a la posibilidad de aprovechar el conocimiento sobre las cianobacterias como indicadores de los niveles de recursos del suelo y poder emplear dicha información para la toma de decisiones.

El trabajo desarrollado fue financiado por la Universidad Nacional de Entre Ríos. Trabajan en el tema Dra. María Gabriela Cano (UNLP), Bioquímica Silvana Raquel Spizzo (UNER), Dra. Silvia Mercedes Benintende (UNER), Ing. Agr. María Cristina Benintende (UNER). 